\title{
Pathology of the heart in the tenth decade
}

\author{
ARIELA POMERANCE 1 \\ From the Department of Histopathology, Central Middlesex Hospital, London
}

SYNOPSIS The pathology of the heart was studied in 60 patients dying in their tenth decade in a general hospital. The severity of coronary atherosclerosis and the incidence of ischaemic heart disease was lower than in younger geriatric patients. The incidence of minor 'aging' changes was similar to that in younger patients with the exception of mitral valve atheroma where the increase with aging continued into the tenth decade. Marked nodular thickening of the tricuspid valve was seen only in males. Over half the systolic murmurs heard were associated with mitral valve abnormalities and not with aortic valve changes. Multiple cardiac pathology was more frequent than in younger patients but its association with failure was much less striking. It is concluded that resistance to the development of coronary atherosclerosis and to failure being precipitated by the multiple minor cardiac abnormalities associated with aging are important factors in attaining extreme longevity.

As cardiovascular disease is the main cause of death in adults, the hearts of patients with exceptionally long life spans are of considerable interest. Survival into the tenth decade is still relatively uncommon and few pathological studies have been made on such people. The largest group consists of 40 nonagenarians from a south London geriatric research unit (Howell, 1963; $1964 \mathrm{a}$ and b); McKeown's (1965) Belfast series included only 19 cases over 90 years. The present communication describes and discusses the cardiac findings in 60 patients in their tenth decade dying in a large general hospital.

\section{CLINICAL FINDINGS}

There were 26 males and 34 females, aged between 90 and 98 years at death (Table I). Almost threequarters of these patients had been in normal rhythms: auricular fibrillation was the commonest abnormality $(17 \%)$ and other abnormalities inincluded multiple extrasystoles and complete heart block. Hypertension appeared relatively uncommon $(10 \%)$, only one male and five females having readings of $200 / 100 \mathrm{~mm} \mathrm{Hg}$ or above. Heart murmurs were heard in $31 \%$ of the males and $44 \%$ of females. These were almost all systolic, of variable characteristics, and no correlation between the site, intensity, and conduction described clinically and the subsequent pathological findings could be

${ }^{1}$ In receipt of a grant from the British Heart Foundation.

Received for publication 7 August 1967.
TABLE I

\begin{tabular}{|c|c|c|c|}
\hline CLINICA & FINDING & & \\
\hline & Males & Females & Total \\
\hline Rhythm & & & \\
\hline Regular & $18(70 \%)$ & $27(80 \%)$ & $45(75 \%)$ \\
\hline Fibrillating & $7(27 \%)$ & $3(9 \%)$ & $10(17 \%)$ \\
\hline Multiple extrasystoles & $\mathbf{0}$ & 2 & 2 \\
\hline Flutter & 0 & 1 & $\mathbf{1}$ \\
\hline Complete atrioventricular block & 1 & 1 & 2 \\
\hline Cardiac Failure & $11(42 \%)$ & $14(41 \%)$ & $25(41 \%)$ \\
\hline $200 / 100 \mathrm{~mm} \mathrm{Hg}$ or higher & 1 & 5 & $6(10 \%)$ \\
\hline Heart Sounds & & & \\
\hline $\begin{array}{l}\text { Systolic murmur } \\
\text { Diastolic murmur }\end{array}$ & $\left.\begin{array}{l}8 \\
2\end{array}\right\}(31 \%)$ & $\left.\begin{array}{r}15 \\
1\end{array}\right\}(44 \%)$ & $23(40 \%)$ \\
\hline Electrocardiograph Findings & & & \\
\hline Non-contributory & 1 & 4 & 5 \\
\hline Suggesting ischaemia & 2 & 0 & 2 \\
\hline Left ventricular hypertrophy & 1 & 2 & 3 \\
\hline Complete atrioventricular block & 1 & 1 & 2 \\
\hline Right bundle branch block & 1 & 2 & 3 \\
\hline Wandering pacemaker & 0 & 1 & 1 \\
\hline Myocardial damage? cause & 1 & 0 & 1 \\
\hline
\end{tabular}

established. Cardiac failure was present in $40 \%$ of cases. Recent electrocardiograms were available for 17 patients, and the abnormalities found included myocardial infarction, probable ischaemia, left ventricular hypertrophy, complete and bundle branch blocks, wandering pacemaker, and non-specific myocardial damage.

\section{PATHOLOGY}

ATHEROMA AND ISCHAEMIC HEART DISEASE Coronary atherosclerosis was sufficiently uniform for a rough 
quantitative assessment in 58 hearts, and was graded as slight in $36 \%$, moderate in $35 \%$, and marked in only $29 \%$ (Table II). This is in contrast to Howell's (1964a) finding of marked coronary atheroma in $60 \%$ of 13 males and 27 females and slight in only $17.5 \%$. In the present series atherosclerosis was less severe in the females; $41 \%$ showed slight narrowing and only $18 \%$ marked narrowing compared with $27 \%$ and $42 \%$ respectively in the males. The severity of coronary and aortic atheroma was similar in almost two-thirds of cases; coronary disease was noticeably more marked than aortic in $8 \%$, and aortic atherosclerosis than coronary in $30 \%$. There was no significant difference between the sexes in this respect.

\section{TABLE II}

ATHEROSCLEROSIS AND MYOCARDIAL CHANGES

\begin{tabular}{|c|c|c|c|}
\hline & Males & Females & Total \\
\hline & 26 & 34 & 60 \\
\hline $\begin{array}{l}\text { Coronary atherosclerosis } \\
\text { Slight } \\
\text { Moderate } \\
\text { Marked }\end{array}$ & $\begin{array}{r}7(27 \%) \\
8(31 \%) \\
11(42 \%)\end{array}$ & $\begin{array}{r}14(41 \%) \\
12(35 \%) \\
6(18 \%)\end{array}$ & $\begin{array}{l}21(36 \%) \\
20(35 \%) \\
17(29 \%)\end{array}$ \\
\hline $\begin{array}{l}\text { Myocardial fibrosis/infarcts with } \\
\text { moderate or marked coronary } \\
\text { disease } \\
\text { Interstitial/paravascular fibrosis } \\
\text { with slight coronary narrowing } \\
\text { only }\end{array}$ & $9(35 \%)$ & $10(34 \%)$ & $19(31 \%)$ \\
\hline Senile cardiac amyloidosis & $16(62 \%)$ & $14(41 \%)$ & $30(50 \%)$ \\
\hline $\begin{array}{l}\text { Hypertrophy of myocardium } \\
\text { (over } 400 \mathrm{~g} \text { ) } \\
\text { Atrophy of myocardium } \\
\quad \text { (under } 300 \mathrm{~g} \text { ) }\end{array}$ & $\begin{array}{l}9(35 \%) \\
2(8 \%)\end{array}$ & $\begin{array}{l}6(18 \%) \\
12(36 \%)\end{array}$ & $\begin{array}{l}15(25 \%) \\
14(23 \%)\end{array}$ \\
\hline
\end{tabular}

Ischaemic myocardial changes were present in 19 cases $(31 \%)$. Two of the 20 hearts with moderate coronary disease had healed infarcts, four patchy focal fibrosis, and one a fine diffuse fibrosis. Of the 11 males with marked coronary atherosclerosis, three had no apparent gross or microscopic fibrosis; all six females in this group had severe ischaemic changes which included two recent infarcts, both asociated with a thrombotic occlusion and one of which had ruptured, and a ventricular aneurysm. Although 12 of the cases with ischaemic lesions had been in failure, death was attributed to ischaemic heart disease in only five and the remaining seven had been free from cardiac symptoms. In Howell's (1963) series death was attributed to coronary disease in $30 \%$ of cases, but equally severe lesions were also observed in patients dying of other causes. A decrease in the incidence of ischaemic heart changes in extreme old age has been noted previously in a smaller group of nonagenarians (Pomerance, 1965) and a similar fall was reported by
McKeown (1965) in the ninth decade; there were no examples of ischaemic heart disease in her 19 cases. in the tenth decade.

OTHER MYOCARDIAL FINDINGS Table II summarizes this information.

HYPERTROPHY AND ATROPHY Hearts weighed between 300 and $400 \mathrm{~g}$ in $31(51 \%)$ patients. $\mathrm{Al}=\overrightarrow{\mathrm{O}}$ though the total number of patients with larger orsmaller hearts was approximately equal, 12 of the $14 \overrightarrow{\mathrm{\omega}}$ $(23 \%)$ with hearts less than $300 \mathrm{~g}$ were female, while? nine of the $15(25 \%)$ with hearts weighing over? $400 \mathrm{~g}$ were male. Marked divergences from theseweights were uncommon; only three hearts weighed $\dot{\omega}$ less than $250 \mathrm{~g}$ and two over $500 \mathrm{~g}$. The smallest heart $(200 \mathrm{~g})$ was from a woman dying of carcinoma of the gall bladder; the largest $(540 \mathrm{~g})$, from $\mathrm{a}^{\mathrm{S}}$ woman dying of left ventricular failure with calcified aortic stenosis and ischaemic heart disease. Ischae-a mic heart disease was present in five of the patients with hypertrophied hearts, in four with hyperten- $\frac{\bullet}{\circ}$ sion; both these conditions in one; and rheumatico mitral disease and cirrhosis of the liver in one응 patient each. Compared with the $40 \%$ incidence in the group as a whole, the cases with small heartso included a lower proportion with failure $(28 \%)$ and

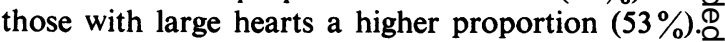
This finding agrees with Sonnek's (1954) that the small heart is less likely to fail. A conspicuously3 brown myocardium (brown atrophy) was noted in only three hearts, one of which was from a patient ino failure. Only one weighed less than $300 \mathrm{~g}$.

Cardiomyopathy Fibrosis in an elderly heart iso? usually attributed to atherosclerosis, even in the absence of appropriate coronary disease. Kline, Kline, and Saphir (1963), however, differentiatedO between ischaemic and non-arteriosclerotic myocardial changes and showed that the latter were not? uncommon in persons over 70 years. In the present series six patients with minimal coronary atherosclerosis had patches of interstitial or paravascular 0 fibrosis and were therefore most appropriately classified as cardiomyopathy (British Medical Journal, 1963).

Senile cardiac amyloidosis The incidence of this? condition continued to increase with age (Pomeso rance, 1966b) and it was present in $62 \%$ of male ando $41 \%$ of female nonagenarians; in four of the female? cases deposits were minimal.

VALVULAR FINDINGS These are set out in Table III $\cong$

Calcific aortic stenosis Jokipii (1963) has stated@ that this is the most common valvular disease in the elderly, and Bedford and Caird (1960) found 130 
TABLE III

VALVULAR CHANGES

\begin{tabular}{|c|c|c|c|}
\hline & Males & Females & Total \\
\hline & 26 & 34 & 60 \\
\hline \multicolumn{4}{|l|}{ Mitral Valve } \\
\hline \multirow{5}{*}{$\begin{aligned} \text { Endocarditis - } & \text { chronic rheumatic } \\
& \text { bacterial } \\
& \text { thrombotic } \\
& \text { acute necrotising }\end{aligned}$} & 1 & 2 & 3 \\
\hline & $i$ & 2 & 3 \\
\hline & 1 & 2 & 3 \\
\hline & - & 1 & 1 \\
\hline & & $\begin{array}{l}\text { (overlyir } \\
\text { calcifica }\end{array}$ & n) \\
\hline
\end{tabular}

Non-specific scarring and chronic inflammatory changes

Mucoid degeneration

Ring calcification $\begin{array}{rrr}1 & 1 & 2 \\ 7(25 \%) & 5(15 \%) & 12(20 \%) \\ 9(35 \%) & 22(65 \%) & 31(52 \%)\end{array}$

Nodular thickening

$\begin{array}{lrrr}\text { Slight (normal) } & 9(35 \%) & 9(27 \%) & 18(30 \%) \\ \text { Moderate } & 8(31 \%) & 14(41 \%) & 22(37 \%) \\ \text { Marked } & 4(15 \%) & 7(20 \%) & 11(18 \%) \\ \text { Not assessable } & 5(19 \%) & 4(12 \%) & 9(15 \%)\end{array}$

Atheroma

$\begin{array}{lcrr}\text { Slight } & 2(8 \%) & 2(6 \%) & 4(7 \%) \\ \text { Moderate } & 14(53 \%) & 14(41 \%) & 28(47 \%) \\ \text { Marked } & 8(31 \%) & 13(38 \%) & 21(35 \%) \\ \text { Not assessable } & 2(8 \%) & 5(15 \%) & 7(11 \%) \\ & & & \\ & 9(33 \%) & 11(33 \%) & 20(33 \%) \\ \text { adhesion } & 10(39 \%) & 11(33 \%) & 21(35 \%) \\ \text { mmissures } & 2 & 0 & 2 \\ & 7(28 \%) & 5(15 \%) & 12(20 \%) \\ \text { ndocarditis } & 1 & 1 & 2\end{array}$

Aortic Valve

Calcification

Commissural adhesion

Broadened commissures

Fenestration

Thrombotic endocarditis

Tricuspid Valve

Nodular

thickening None (normal)

Slight

Moderate

Scarring and fibrosis 2

Ulceration

$\begin{array}{lll}6(23 \%) & 18(53 \%) & 24(40 \%) \\ 6(23 \%) & 10(29 \%) & 16(27 \%) \\ 8(31 \%) & 4(12 \%) & 12(20 \%) \\ 6(23 \%) & 2(6 \%) & 8(13 \%) \\ 2 & 0 & 2 \\ 4 & 1 & 5\end{array}$

Pulmonary Valve

Nodules (morganii)

Fenestration

$\begin{array}{cc}10(40 \%) & 11(33 \%) \\ 1 & 2\end{array}$

cases in their 28 patients over 90 years with valvular heart disease. Although macroscopic calcification was present in the valve fibrosa in almost one third of the 60 nonagenarians from this hospital and in Howell's (1964a) 40 cases, this was severe enough to cause stenosis in only one case, and there were no examples of calcification with commissural fusion in either series.

Rheumatic mitral disease The existence of this condition in old age is now well recognized. Cases in the tenth decade were reported by Howell and Piggot (1951), by Jokipii and Heino (1963), and by Bedford and Caird (1960). In the present series, mitral stenosis of rheumatic type was seen in three patients, a man of 92 and two women aged 90 and 92 respectively. The cusps were greatly thickened, opaque and distorted with commissural fusion and short thick chordae tendineae but no valve calcification. One woman and the man had complete heart block.

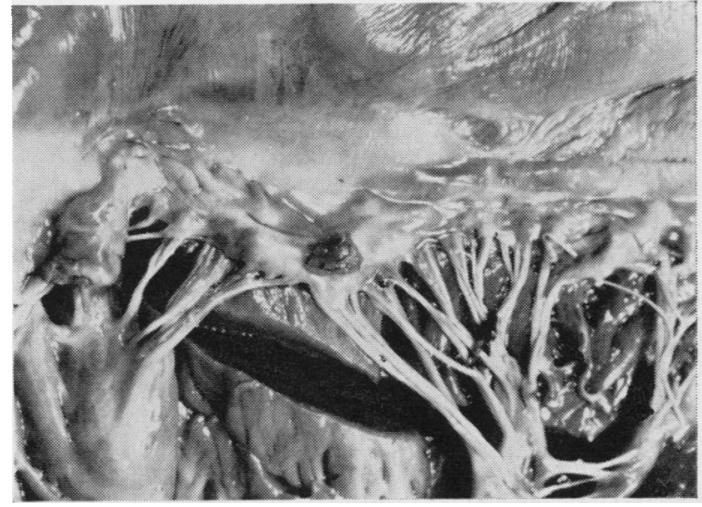

FIG. 1. Opened left side of heart showing a pedunculated vegetation on the anterior cusp of the mitral valve (from a woman aged 91 dying of congestive cardiac failure and carcinoma of stomach). $\times 1 \frac{1}{2}$ approximately.

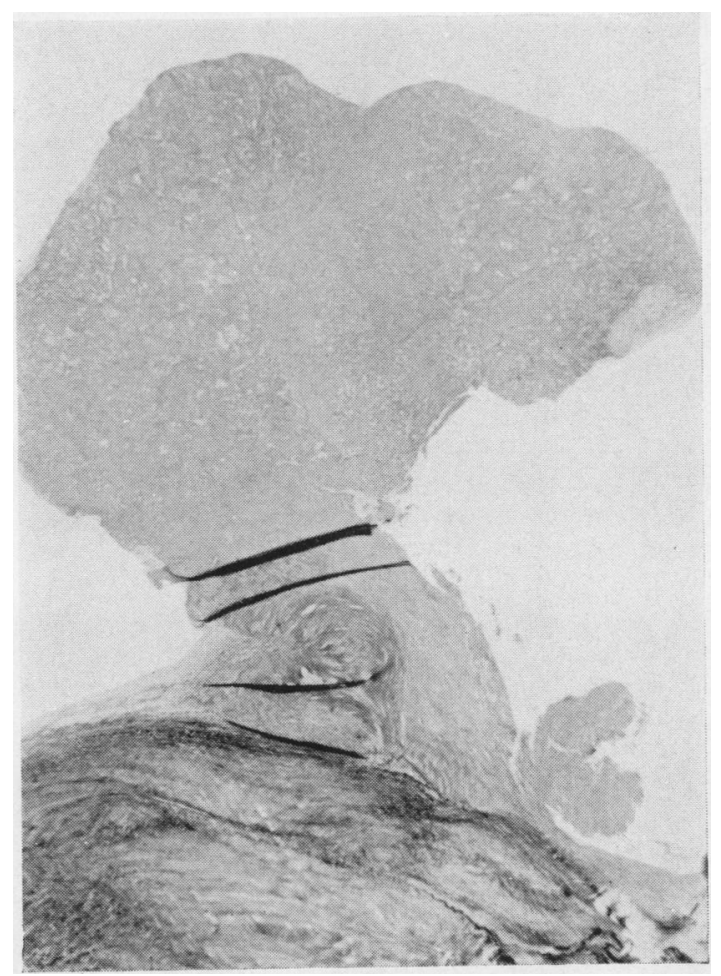

FIG. 2. Photomicrograph showing thrombotic vegetation attached to a mitral valve endocardium (from a woman aged 93 dying of bronchopneumonia and cardiac failure). Elastic Van Giesen. $\times 30$.

Other forms of endocarditis Non-bacterial (thrombotic) endocarditis (Figs. 1 and 2) was present on the anterior mitral cusps of three patients with 
otherwise normal valves and on the aortic valve of the male with rheumatic heart disease. Bacterial endocarditis was seen in three cases, all involving the posterior mitral cusp. In the male the chordae tendineae were necrotic and a less severe infection was present in the apposing cusp surface. In the females, the endocarditis was only apparent on microscopy, having developed in areas of valvulitis over mitral ring calcification. Minor degrees of non-specific scarring and distortion and minor microscopic post-inflammatory changes were seen in the mitral valve of one patient of each sex, and two other males showed thickening and distortion of the anterior tricuspid leaflets, with thick adherent chordae tendineae. The pathogenesis of these lesions has already been discussed (Pomerance, 1965, 1967a) and, as with non-arteriosclerotic myocardial fibrosis, was thought to result from non-specific inflammatory changes which may occur in Coxsackie (Smith, 1967), upper respiratory tract, and similar relatively minor infections of undiagnosed origin (Lancet, 1967).

Mitral ring calcification Although the incidence of this condition increases with age the pathogenesis cannot be attributed to involutional changes alone (Pomerance, 1967a and b; McKeown, 1965). Realization of its clinical significance is comparatively recent (Korn, DeSanctis, and Sell, 1962) and few pathological studies are available. It was noted in $20 \%$ of Howell's (1964a) nonagenarian group and was present in $52 \%$ of the present series. It wa: almost twice as frequent in females $(65 \%)$ as in males (35\%) and tended to be more severe. Massive calcification with spikes of calcareous material distorting the posterior cusp was seen in only two males but in nine females. Two females showed

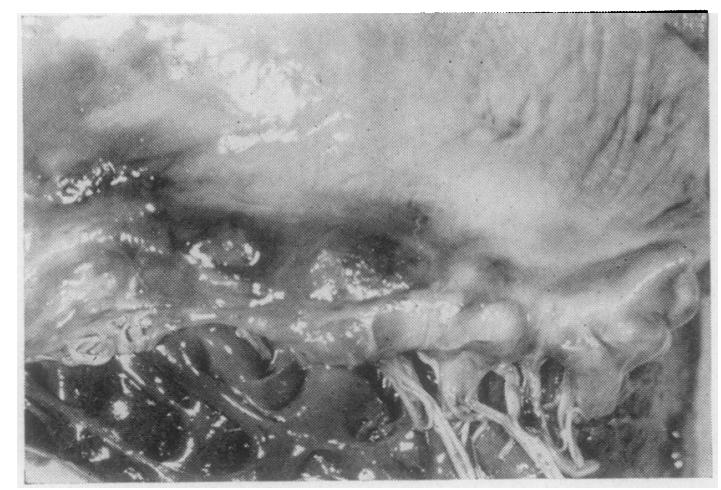

FIG. 3. Posterior wall of left atrium and ventricle showing haemorrhagic discoloration over irregular mitral ring calcification which is distorting the posterior cusp (from a woman aged 93 with rheumatoid arthritis, dying of acute bronchitis and bronchopneumonia). $\times 1 \frac{1}{2}$ approximately. haemorrhagic necrotizing valvulitis in relation to calcified masses (Fig. 3); in one, severe acute inflam- matory changes extended for several millimetres $\overrightarrow{\vec{s}}$ into the surrounding myocardium. Bacteria infection of inflamed valves had also occurred in $\frac{\odot}{0}$ two cases. Mitral incompetence was demonstrated $\overline{\bar{n}}$ by marked left atrial dilatation in one case and a 'jet' lesion on the posterior atrial wall in another and systolic murmurs had been noted in all patients $s^{\infty}$ in whom the heart sounds had been clearly audible. $\overrightarrow{0}$ MISCELLANEOUS MINOR FINDINGS Mild or moderate 'ballooning' (mucoid degeneration) occurred in $20 \%$ of posterior mitral cusps but no severe examples of this change were seen.

Nodular thickening was present to some degree at the line of apposition of all anterior mitral cusps but was marked ('senile' sclerosis) in only $18 \%$. Lipoid plaques were also present on the ventricular? surface of this cusp in all cases, and to a marked $\overrightarrow{-}$ degree in $35 \%$. There was little quantitative diffe rence between the sexes. The incidence of calcification, commissural adhesions, and fenestration of semi-lunar valves was also similar but tricuspid changes were more frequent in males, only응 six $(23 \%)$ having normal thin, translucent cusps compared with $18(53 \%)$ of females. Six males $(23 \%)$ showed nodular thickening of this valve; post inflammatory changes were present in two; ank small superficial ulcers were superimposed on the thickened plaques in four cases. These 'aging 3 changes have already been fully discussed (Pome? rance, 1966a; 1967a and b).

MULTIPLE PATHOLOGY Multiple lesions increase in frequency with age (Howell, 1964a). This is true in the heart as well as in the body as a whole, and there is a striking difference in the incidence of multiples cardiac pathology in elderly patients with and with-out cardiac failure (Pomerance, 1965). Although the proportion of hearts with multiple abnormalities was higher in the tenth decade, this difference was much smaller than in younger patients; $87 \%$ of hearts from cases of failure showed multiple patho logy, but so did $48 \%$ of those from patients withou? clinical cardiac disease.

CARDIAC MURMURS AND PATHOLOGICAL FINDING Systolic murmurs had been heard in 15 females and eight males. Six, all in females, were described as aortic ejection type, the remainder as 'apical' of 'mitral'. Two aortic murmurs were associated witlę severe degenerative aortic cusp calcification, one showed minimal aortic and mitral ring calcification but marked mitral nodular thickening, and in twe others the aortic cusps were normal but the mitrad 
valve ring was heavily calcified; in the sixth case the only valvular abnormality was minimal aortic commissural adhesions, but the patient had been hypertensive $(250 / 100 \mathrm{~mm} \mathrm{Hg})$ and also showed slight aneurysmal dilatation of the membranous interventricular septum. The findings in the males with 'mitral' or apical systolic murmurs were mitral ring calcification, mild aortic cusp calcification, post-inflammatory distortion of the tricuspid and mitral valve in one case each, slight mitral and aortic calcification, and mitral ring calcification with posterior cusp 'ballooning' also in one case each, and 'ballooning' (ie mucoid degeneration of the mitral valve) alone in two cases. In the females, mitral ring calcification was found in four cases, rheumatic mitral stenosis and ring calcification, mitral thrombotic endocarditis and aortis cusp calcification, thrombotic endocarditis and mitral ring calcification, and mitral ring calcification with 'ballooning' in one case each. One patient had no cardiac abnormality but a blood pressure of 220/120 $\mathrm{mm} \mathrm{Hg}$.

\section{COMMENT}

Relatively little is known of the pathology of extreme old age and any studies on patients in the tenth decade are therefore of considerable academic interest, and may help to dispel such common misconceptions as the association of brown atrophy with aging. Their main value, however, is in the identification of factors which may have contributed to the unusually long life span, and in this context two findings in the present group were relevant: the low incidence of ischaemic heart disease and the decreased association of multiple pathology with failure, compared with younger groups.

The presence of ischaemic heart disease in less than one third of patients in the tenth decade confirmed the falling incidence in extreme old age previously noted in smaller series (Pomerance, 1965; McKeown, 1965) and contradicts the widely held view that geriatric heart disease is synonymous with ischaemic heart disease. However, the theory of Russek, Zohman, Doerner, Russek, and White (1951) that absence of severe coronary atherosclerosis might be a prerequisite to the attainment of old age was not confirmed either; severe coronary changes were present in $29 \%$ of hearts. The continuing increase in mitral valve atheroma independently of coronary disease was also of interest, indicating that intimal lipoid changes continue to progress with age. This suggests that the relative freedom from coronary atherosclerosis resulted from resistance to development of complicated atheroma lesions rather than from biochemical factors influencing lipoid metabolism.

The decreased association between multiplicity of pathology and failure was more unexpected than the fall in ischaemic heart disease. In younger geriatric patients multiple pathology was five times as frequent in failure cases (Pomerance, 1965); the incidence increased with age, but although this increase continued in the tenth decade, the multiple pathology was only about twice as frequent in the failure cases in this age group.

It seems, therefore, that the hearts of people with unusually long life spans show not only unusual resistance to ischaemic changes but also an exceptional capacity to tolerate the other increasing and multiple cardiac abnormalities of aging, without failure. Studies on factors associated with the absence of coronary disease in the elderly (Brown and Ritzmann, 1967) and the well known familial pattern of longevity suggest that this resistance to atherosclerosis and failure is likely to be genetically determined.

\section{REFERENCES}

Bedford, P. D., and Caird, F. I. (1960). Valvular Diseases of the Heart in Old Age. Churchill, London.

British Medical Journal (1963). Annotation, 1, 1304.

Brown, R. C., and Ritzmann, L. (1967). J. Amer. geriat. Soc., 15, 239. Howell, T. H. (1963). Geriatrics, 18, 899.

- (1964a). J. Amer. geriat. Soc., 12, 410.

- (1964b). Geront. clin. (Basel), 6, 292.

- and Piggot, A. P. (1951). Geriatrics, 6, 85.

Jokipii, S. G. (1963). Ann. intern. Med., 52, suppl. 40, 3.

- and Heino, A. E. (1963). Ann. Med. Fen 52 supp. 40, 13.

Kline, I. K., Kline, T. S., and Saphir, O. (1963). Amer. Heart J., 65, 446. Korn, D., DeSanctis, R. W., and Sell, S. (1962). New Engl. J. Med., 267, 900.

Lancet (1967). Leading article 1, 883.

McKeown, F. (1965). Pathology of the Aged. Butterworths, London.

Pomerance, A. (1965). Brit. Heart J., 27, 696.

- (1966a). Ibid., 28, 815.

(1966b). J. Path. Bact., 91, 357.

(1967a). Brit. Heart J., 29, 222.

- (1968). Geriatrics, 23, 101 .

Russek, H. I., Zohman, B. L., Doerner, A. A., Russek, A. S., and White, L. G. (1951). J. Amer. med. Ass., 147, 1731 .

Sonnek, P. J. (1954). Geriatrics, 9, 75.

Smith, W. G. (1967). Amer. Heart J., 73, 439. 